\title{
Effects of lipase inhibition on gastric emptying of, and on the glycaemic, insulin and cardiovascular responses to, a high-fat/carbohydrate meal in type 2 diabetes
}

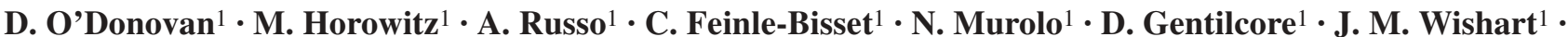 \\ H. A. Morris ${ }^{1}$ K. L. Jones ${ }^{1}$ \\ ${ }^{1}$ Department of Medicine, University of Adelaide, Royal Adelaide Hospital, Adelaide, Australia
}

\begin{abstract}
Aims/hypotheses. We examined the effects of lipase inhibition with orlistat on (i) gastric emptying of, and (ii) the glycaemic, glucagon-like peptide-1 (GLP-1) and cardiovascular responses to, a high-fat/carbohydrate meal in type 2 diabetic patients.

Methods. Eight type 2 diabetic patients, who were aged 62 years (median range: 49-68 years) and managed by diet alone, consumed a meal containing $65 \mathrm{~g}$ powdered potato, $20 \mathrm{~g}$ glucose reconstituted with $200 \mathrm{ml}$ water (labelled with $20 \mathrm{MBq}{ }^{99 \mathrm{~m} T c-s u l p h u r-c o l l o i d)}$ and $45 \mathrm{~g}$ margarine. They did this on two separate occasions, with and without $120 \mathrm{mg}$ orlistat, and while in the seated position with their back against a gamma camera. Venous blood samples for measurement of blood glucose, plasma insulin and GLP-1 were obtained immediately before the meal and at regular intervals afterwards. Blood pressure (systolic and diastolic) and heart rate were measured using an automated device.
\end{abstract}

Results. Gastric emptying of the meal was faster after orlistat than without orlistat $(50 \%$ emptying time $[$ mean $\pm \mathrm{SEM}], 61 \pm 8 \mathrm{~min}$ vs $98 \pm 5 \mathrm{~min} ; p=0.0001)$. In the first $60 \mathrm{~min}$ after the meal blood glucose $(p=0.001)$ and plasma insulin $(p=0.01)$ concentrations were higher in patients who had taken orlistat; between 60 and 180 min plasma GLP-1 $(p=0.02)$ concentrations were lower after orlistat than without orlistat. Between 0 and 30 min systolic blood pressure $(p=0.003)$ was lower, and heart rate $(p=0.03)$ greater in subjects who had taken orlistat than in those who had not.

Conclusions/interpretation. Inhibition of fat digestion by orlistat may-as a result of more rapid gastric emptying - exacerbate postprandial glycaemia and the postprandial fall in blood pressure in patients with type 2 diabetes after ingestion of meals containing fat and carbohydrate.

Keywords Gastric emptying - Glucagon-like peptide-1 . Glycaemic control · Orlistat · Type 2 diabetes.
Received: 16 March 2004 / Accepted: 18 July 2004

Published online: 15 December 2004

(C) Springer-Verlag 2004

K. L. Jones (- )

Department of Medicine, University of Adelaide,

Royal Adelaide Hospital, North Terrace, Adelaide,

SA 5000, Australia

E-mail: karen.jones@adelaide.edu.au

Tel.: +61-8-82225394, Fax: +61-8-82233870

Abbreviations: GIP, glucose-dependent insulinotropic polypeptide · GLP-1, glucagon-like peptide-1 - T50, gastric emptying half-time

Conflict of Interest: None of the authors have a conflict of interest in relation to this study.

\section{Introduction}

Optimisation of glycaemic control, usually assessed by glycated haemoglobin, represents a major component of the management of type 2 diabetes. Postprandial glycaemia influences glycated haemoglobin [1] and may also be an independent risk factor for macrovascular disease $[2,3]$. The rate of gastric emptying of carbohydrate is now known to be a major determinant of postprandial glucose concentrations in healthy subjects [4] and patients with type 2 diabetes [5].

We have reported that the incorporation of the lipase inhibitor, orlistat, into a drink containing oil $(60 \mathrm{ml})$ and glucose $(75 \mathrm{~g})$, consumed in the left lateral 
decubitus position, accelerates gastric emptying of fat and glucose and potentiates the postprandial rises in blood glucose and plasma insulin in patients with type 2 diabetes [6]. These observations were not surprising, given that the regulation of gastric emptying of fat is known to be dependant on lipolysis [7, 8]. Orlistat also attenuated the incretin hormone (glucagon-like peptide-1 [GLP-1] and glucose-dependent insulinotropic polypeptide [GIP]) responses to the drink [6]. While orlistat has been reported to induce weight loss and improve glycated haemoglobin in obese type 2 patients $[9,10,11]$ and is used widely, to our knowledge, information relating to postprandial glycaemia is limited to one study, in which postprandial blood glucose concentrations were measured once, at 2 hours after a meal of unspecified composition [11]. Our recent observations [6] suggest that lipase inhibition may adversely affect postprandial glycaemia in type 2 diabetes. However, the study was designed to evaluate mechanisms and the liquid 'meal' used can be considered unphysiological because of its composition and palatability, as well as the position of the subject during the study. Accordingly, we have now evaluated the effects of lipase inhibition on gastric emptying, glycaemia and GLP-1 levels in response to a more physiological meal consumed in the upright posture.

Postprandial hypotension occurs frequently in older subjects, particularly those with diabetes, and represents a major clinical problem by predisposing to syncope and falls $[12,13,14]$. The maximum fall in blood pressure (most evident for systolic blood pressure) and increase in heart rate are usually evident within 30 min of a meal [14]. The magnitude of these changes is critically dependent on meal composition: glucose has a major effect and there is little, if any, change in blood pressure after ingestion of protein or fat [15]. We have recently established, in healthy, older subjects [16] and in type 2 diabetic patients [17], that the postprandial fall in blood pressure and increase in heart rate are influenced by the rate at which glucose enters the small intestine, i.e. when gastric emptying is more rapid, the fall in blood pressure is greater. We therefore reasoned that acceleration of gastric emptying of the carbohydrate component of a fat/carbohydrate meal by orlistat could exacerbate the postprandial fall in blood pressure and increase in heart rate.

The aims of this study, therefore, were to evaluate in type 2 diabetic patients the acute effects of lipase inhibition with orlistat on (i) gastric emptying of, and (ii) the glycaemic, GLP-1 and cardiovascular responses to, a carbohydrate/fat meal.

\section{Subjects, materials and methods}

Subjects. Eight type 2 diabetic patients (five men, three women), who were aged 62 years (median range: 49-68), had a
BMI of $27.6 \mathrm{~kg} / \mathrm{m}^{2}$ (median range: 21.9-36.1) and were managed by diet alone, participated in the study. All patients met World Health Organization criteria for the diagnosis of diabetes. The duration of known diabetes was $2.5(1.5-12)$ years, and glycated haemoglobin was $6.5 \%(5.3-7.0 \%)$ (normal range: $4-6 \%$ ). Two subjects smoked (but smoking was prohibited on the study days), and none consumed more than $20 \mathrm{~g}$ alcohol per day. No subject was taking medication known to affect gastrointestinal function, appetite or glycaemia. The protocol was approved by the Research Ethics Committee of the Royal Adelaide Hospital and each subject gave written, informed consent.

Study protocol. Each subject attended the Department of Nuclear Medicine, PET and Bone Densitometry at approximately 09.30 hours after an overnight fast (14 h for solids, $12 \mathrm{~h}$ for liquids) [6] on two occasions, which were separated by 3 to 7 days. An automated blood pressure cuff (DINAMAP; Johnson \& Johnson, Tampa, Fla., USA) was placed around the left arm for measurement of blood pressure and heart rate [16, 17] and an intravenous cannula was inserted into the right antecubital vein for subsequent blood sampling. The subject was then seated with his or her back against a gamma camera and allowed to rest comfortably for $\sim 30 \mathrm{~min}$ before consuming a meal consisting of $65 \mathrm{~g}$ powdered potato (Deb, Epping, NSW, Australia), reconstituted with $200 \mathrm{ml}$ water containing $20 \mathrm{~g}$ glucose and $45 \mathrm{~g}$ margarine (Fairy Cooking margarine, Epping, NSW, Australia) and labelled with $20 \mathrm{MBq} 99 \mathrm{mTc}-$ sulphur-colloid. The energy content of the meal was 2,600 kJ (total fat $40 \mathrm{~g}$, total carbohydrate $62 \mathrm{~g}$ ). Subjects consumed the meal over $10 \mathrm{~min}$. On one of the two days, $120 \mathrm{mg}$ of orlistat (Xenical; Hoffmann-La Roche, Basel, Switzerland) was mixed into the meal, in double-blind, randomised fashion, i.e. the individual(s) who presented the meal to the subjects and subsequently analysed the data were unaware whether the meal contained orlistat or not. The rationale for including orlistat in the meal was that the lipase inhibitor would be active intragastrically and its delivery into the small intestine coordinated with gastric emptying of the fat component of the meal [6, 7]. Gastric emptying was assessed for $180 \mathrm{~min}$ after meal consumption. Blood samples were taken at $-15 \mathrm{~min}$, immediately before the meal and then after meal completion at 15-min intervals for $120 \mathrm{~min}$, and thereafter at 30-min intervals until $180 \mathrm{~min}$. Blood pressure and heart rate were also measured immediately before the meal and then for $180 \mathrm{~min}$. Postprandial hypotension was defined as a fall in systolic blood pressure of greater than $20 \mathrm{~mm} \mathrm{Hg}$ within $2 \mathrm{~h}$ of the meal $[12,13,14]$. Cardiovascular autonomic nerve function was evaluated on one day, after completion of the gastric emptying measurement [16, 17]. Subjects were requested to report any potential adverse effects experienced during, or in the $72 \mathrm{~h}$ following, each study.

Gastric emptying. The time of completion of the meal was defined as $t=0 \mathrm{~min}$ [17]. Radio-isotopic data were acquired in 1-min frames for the first $60 \mathrm{~min}$ and 3-min frames for the following $120 \mathrm{~min}$ [6]. Emptying curves were derived for total, proximal and distal gastric regions and expressed as percent retention over time. The $50 \%$ emptying time (T50) and the amounts emptied between 0 to 60 and 60 to 120 min were also derived $[5,6,16]$. Data were corrected for radionuclide decay and gamma ray (tissue) attenuation using established methods [5].

Blood glucose, plasma insulin and plasma GLP-1 concentrations. Blood samples were collected in ice-chilled EDTAtreated tubes containing $400 \mathrm{KIU}$ aprotinin (Trasylol; Bayer Australia, Pymple, Australia) per litre blood. Plasma was sepa- 
rated by centrifugation $\left(3200 \mathrm{~g}, 15 \mathrm{~min}, 4^{\circ} \mathrm{C}\right)$ and stored at $70^{\circ} \mathrm{C}$ for subsequent analysis. Blood glucose concentrations (mmol/l) were determined immediately by the glucose oxidase method using a portable glucose meter (Medisense Precision QID; Abbott Laboratories, Bedford, Mass., USA). The accuracy of this method has been confirmed in our laboratory using the hexokinase technique [4]. Plasma insulin concentrations (mU/l) were measured by ELISA immunoassay (Diagnostics Systems Laboratories, Webster, Tex., USA). The sensitivity of the assay was $0.26 \mathrm{mU} / \mathrm{l}$; the intra-assay coefficient of variation was $2.6 \%$, and the inter-assay coefficient of variation was $6.2 \%$ [6]. Plasma GLP-1 concentrations (pmol/l) were measured by radioimmunoassay. Antibody, supplied by Professor S.R. Bloom (Hammersmith Hospital, London), did not crossreact with glucagon, GIP, or other gut or pancreatic peptides and has been demonstrated by chromatography to measure intact GLP-1 $1_{(7-36)}$ amide. The intra-assay coefficient of variation was $17 \%$, and the inter-assay coefficient of variation was $18 \%$. Sensitivity was $1.5 \mathrm{pmol} / \mathrm{l}[6]$.

Blood pressure and heart rate. Blood pressure (systolic and diastolic) and heart rate were measured before ingestion of the meal and after completion of the meal every 3 min for the first $60 \mathrm{~min}$ and every $6 \mathrm{~min}$ between 60 and $180 \mathrm{~min}[16,17]$.

Cardiovascular autonomic nerve function. Autonomic nerve function was evaluated using standardised cardiovascular reflex tests. Parasympathetic function was evaluated by the variation ( $\mathrm{R}-\mathrm{R}$ interval) of the heart rate during deep breathing and the immediate heart rate response to standing (' $30: 15$ ' ratio). Sympathetic function was assessed by the fall in systolic blood pressure in response to standing. Each test result was scored according to age-adjusted criteria as $0=$ normal, $1=$ borderline or $2=$ abnormal for a total maximum score of 6 . A score of 3 or more was considered to indicate definite autonomic dysfunction $[5,6]$.

Statistical analysis. For all the biochemical variables, the mean of two baseline measurements was used in statistical analysis. Gastric emptying, blood glucose, plasma insulin, plasma GLP1 , blood pressure (systolic, diastolic) and heart rate were evaluated using repeated measures ANOVA with treatment and time as factors. The number of levels of the factor 'time' was dependent on the variable analysed; 10 time points for gastric emptying, 11 for blood glucose, plasma insulin and GLP-1, and 31 for blood pressure and heart rate. Student's paired $t$ tests were used to compare maximum (peak) concentration and baseline measurements. Blood glucose, plasma insulin and GLP-1 were analysed between 0 and $60 \mathrm{~min}$ and 60 and $180 \mathrm{~min}$. For blood glucose, AUCs between 0 and $60 \mathrm{~min}, 0$ and $120 \mathrm{~min}$ and 0 and $180 \mathrm{~min}$ were calculated using the trapezoidal rule. Given that the effects of a meal on blood pressure and heart rate are characteristically maximal within $30 \mathrm{~min}[12,13,14]$, blood pressure and heart rate were analysed for the periods 0 to $30 \mathrm{~min}$ and 30 to $180 \mathrm{~min}$ and expressed as change from baseline [16]. Statistical significance was accepted at a $p$ value of less than 0.05 and data are presented as mean values \pm SEM, unless stated otherwise.

\section{Results}

All subjects tolerated the study well; six of the eight subjects reported side effects after orlistat treatment, all occurring after completion (i.e. after $180 \mathrm{~min}$ ) of the gastric emptying measurement. These included ab- dominal bloating $(n=3)$ and loose and oily stools $(n=6)$. In all cases adverse effects were mild and resolved spontaneously within $48 \mathrm{~h}$. No adverse effects were reported on the control day. No subject had evidence of autonomic nerve damage (score: 1; median range: $0-2)$.

Gastric emptying and intragastric distribution

Total stomach. Total gastric emptying of the meal (Fig. 1a) was faster with orlistat than without (T50: $61 \pm 8$ min vs $98 \pm 5 \mathrm{~min}$; treatment effect: $\mathrm{F}(1)=75$, $p=0.0001)$. The amount emptied between 0 and 60 min was greater than in the 60 to 120 -min period with orlistat $(p=0.0018)$, while there was no significant difference in these time periods in the control study. The rate of energy delivery to the duodenum between 0 and 60 min was greater with orlistat than without (orlistat: $22.7 \pm 1.2 \mathrm{~kJ} / \mathrm{min}$ vs control: $11.7 \pm 1.1 \mathrm{~kJ} / \mathrm{min} ; p=0.0004$ ), while between 60 and $120 \mathrm{~min}$ there was no difference between the two treatments (orlistat: $9.9 \pm 1.2 \mathrm{~kJ} / \mathrm{min}$ vs control: $14.5 \pm 0.9 \mathrm{~kJ} / \mathrm{min})$.

Intragastric distribution. Less of the meal was retained in the proximal stomach after orlistat (Fig. 1b) than without orlistat $(p=0.005)$. There was a trend for less retention of the meal in the distal stomach (Fig. 1c) following orlistat $(p=0.09)$.

Blood glucose, plasma insulin and plasma GLP-1 concentrations

Blood glucose. There was no difference (Fig. 2a) in baseline blood glucose between the two days. There was a rise $(p=0.0001)$ in blood glucose in the first 60 min after the meal on both days. Mean blood glucose between 0 and $60 \mathrm{~min}(p=0.001)$ and peak blood glucose (orlistat: $13.5 \pm 1 \mathrm{mmol} / \mathrm{l}$ vs control: $11.4 \pm 1 \mathrm{mmol} / \mathrm{l} ; p=0.03$ ) were higher after orlistat than control. Between 60 and 180 min there was no significant difference between the two days, although mean blood glucose tended to be less after orlistat between 120 and $180 \mathrm{~min}$. The AUCs for glucose between 0 and $60 \mathrm{~min}$ (orlistat: $658 \pm 34 \mathrm{mmol} / \mathrm{min}$ vs control: $524 \pm 28 \mathrm{mmol} / \mathrm{min} ; p=0.006$ ) and 0 and $120 \mathrm{~min}$ (orlistat: $1414 \pm 82 \mathrm{mmol} / \mathrm{min}$ vs control: $1194 \pm 81 \mathrm{mmol} /$ min; $p=0.007$ ), but not 0 and $180 \mathrm{~min}$ (orlistat: $1932 \pm 123 \mathrm{mmol} / \mathrm{min}$ vs control: $1826 \pm 120 \mathrm{mmol} /$ $\min$ ), were significantly greater after orlistat than control.

Plasma insulin. There was no difference (Fig. 2b) in baseline plasma insulin between the two days. There was a rise $(p=0.0001)$ in plasma insulin in the first $60 \mathrm{~min}$ on both days. Between 0 and $60 \mathrm{~min}$ plasma 

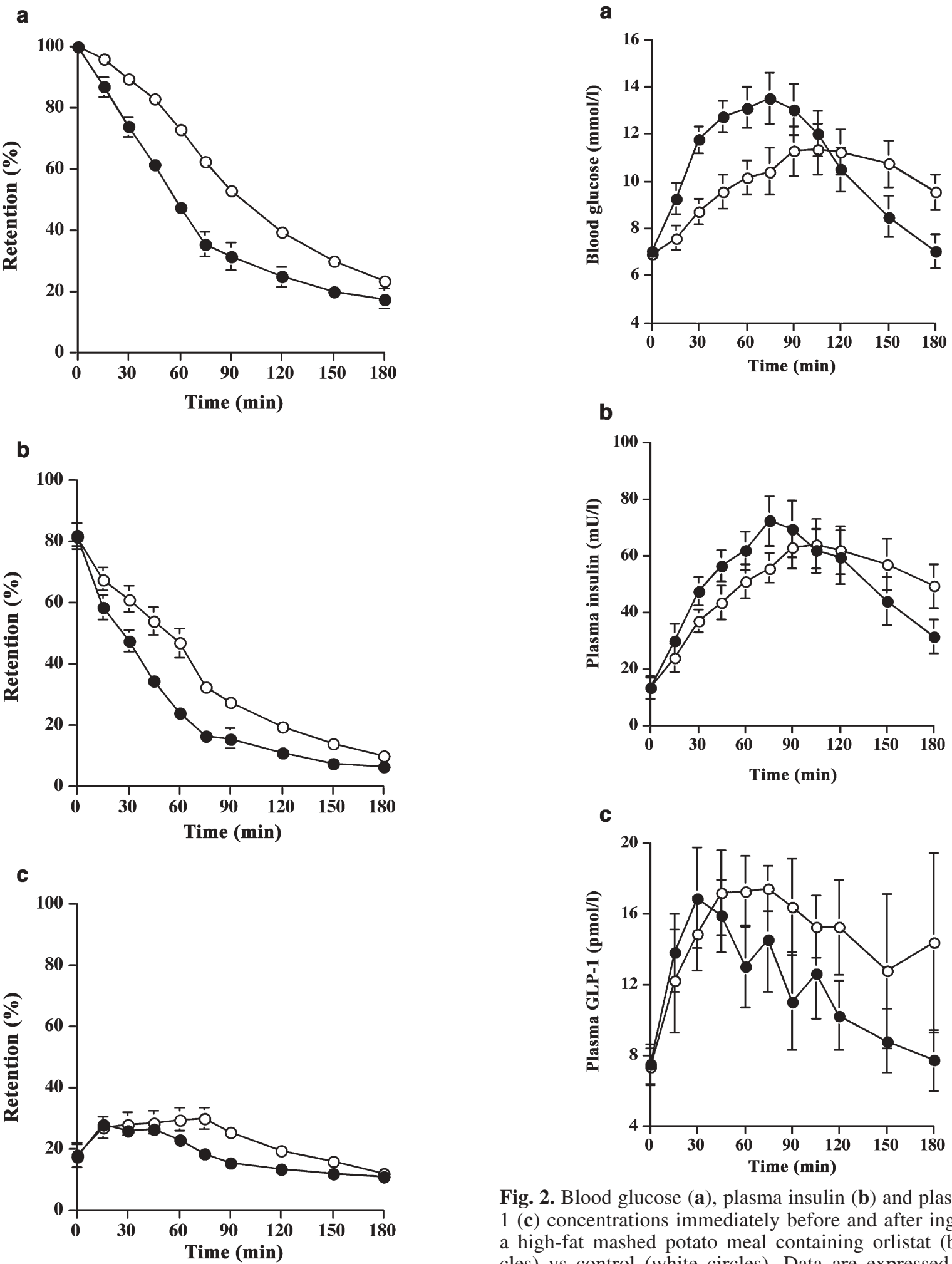

Fig. 1. Total (a), proximal (b) and distal (c) stomach retention of a high-fat mashed potato meal containing orlistat (black circles) vs control (white circles). Data are expressed as mean values $\pm \operatorname{SEM}(n=8)$ between $t=0-180 \mathrm{~min}$

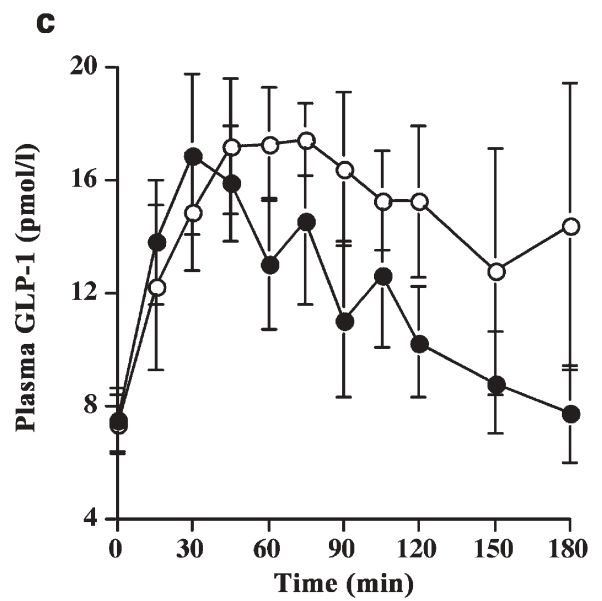

Fig. 2. Blood glucose (a), plasma insulin (b) and plasma GLP1 (c) concentrations immediately before and after ingestion of a high-fat mashed potato meal containing orlistat (black circles) vs control (white circles). Data are expressed as mean values $\pm \operatorname{SEM}(n=8)$ between $t=0-180 \mathrm{~min}$ 

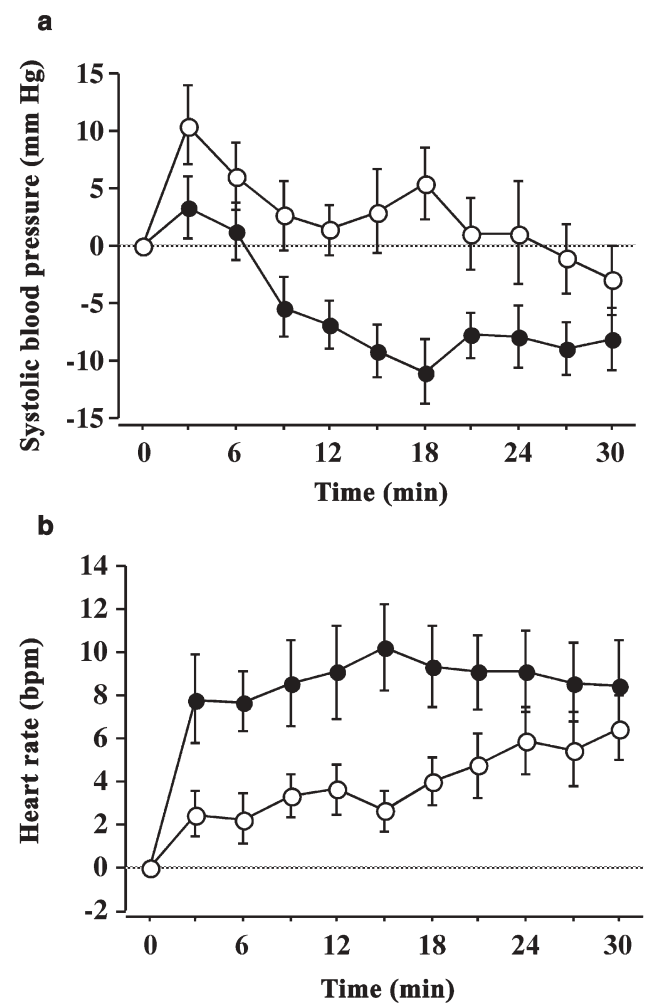

Fig. 3. Change in systolic blood pressure (a) and heart rate in beats per minute (bpm) (b) from baseline after ingestion of a high-fat mashed potato meal containing orlistat (black circles) vs control (white circles). Data are expressed as mean values \pm SEM $(n=8)$ between $t=0-30 \mathrm{~min}$

insulin was higher $(p=0.01)$ after orlistat than in control. However, there was no difference in peak plasma insulin between the two treatments (orlistat: $72.3 \pm 8.7 \mathrm{mU} / 1$ vs control: $64.2 \pm 8.7 \mathrm{mU} / \mathrm{l} ; p=0.14)$. There was no difference in plasma insulin between 60 and $180 \mathrm{~min}$ on the two days.

Plasma GLP-1. There was no difference (Fig. 2c) in baseline plasma GLP-1 between the two days. There was a rise $(p=0.0001)$ in plasma GLP-1 in the first 60 min on both days. Between 0 and $60 \mathrm{~min}$, there was no difference in plasma GLP-1; however, between 60 and $180 \mathrm{~min}$ plasma GLP-1 was lower $(p=0.02)$ following orlistat than in control. There was no difference in peak plasma GLP-1 (orlistat: $16.9 \pm 2.9 \mathrm{pmol} / \mathrm{l}$ vs control: $17.5 \pm 1.3 \mathrm{pmol} / \mathrm{l})$.

\section{Blood pressure and heart rate}

Systolic blood pressure. There was no difference (Fig. 3a) in baseline systolic blood pressure (orlistat: $127 \pm 5 \mathrm{~mm} \mathrm{Hg}$ vs control: $122 \pm 4 \mathrm{~mm} \mathrm{Hg}$ ). There was a fall in systolic blood pressure in the first $30 \mathrm{~min}$ following orlistat $(p<0.003)$, but not control. The magnitude of the fall was greater with orlistat than with control $(p=0.02)$. Two subjects on orlistat and one in the control study had postprandial hypotension (i.e. a fall in systolic blood pressure $>20 \mathrm{~mm} \mathrm{Hg}$ ). Between 30 and $180 \mathrm{~min}$ blood pressure was non-significantly less following orlistat (data not shown).

Diastolic blood pressure. There was no difference in baseline diastolic blood pressure (orlistat: $66 \pm 5 \mathrm{~mm}$ $\mathrm{Hg}$ vs control: $67 \pm 6 \mathrm{~mm} \mathrm{Hg}$ ). After the meal there was no significant difference in diastolic blood pressure between treatments (data not shown).

Heart rate. There was no difference (Fig. $3 b$ ) in baseline heart rate (orlistat: $61 \pm 2$ beats per min vs control: $63 \pm 2$ beats per min). Heart rate increased in the first 30 min after the meal on both days $(p=0.0001)$. This increase was evident by 3 min after orlistat. The magnitude of the increase was greater with orlistat than with control $(p=0.03)$.

\section{Discussion}

This study establishes that in patients with diet-controlled type 2 diabetes the lipase inhibitor, orlistat, when included in a semi-solid, palatable, carbohydrate/fat meal consumed in the seated position: (i) accelerated gastric emptying; (ii) increased the postprandial rises in blood glucose and plasma insulin; (iii) attenuated the plasma GLP-1 response; and (iv) increased the magnitude of the postprandial fall in blood pressure and rise in heart rate, when compared to a control meal that did not contain orlistat.

The increased blood glucose and insulin responses observed by us after orlistat are likely to primarily reflect the acceleration of gastric emptying [6]. Our observations $[6,18,19]$ and those of others [20] indicate that fat (as well as carbohydrate) is a substantial stimulus to the secretion of the incretin hormone GLP-1, and that this is dependent on fat digestion $[6,18]$. In our previous study [6] the GLP-1 (as well as GIP) response was attenuated by orlistat (an effect that has now been confirmed) and may contribute to the less than adequate compensatory increase in plasma insulin and the observed increase in postprandial glucose concentrations. Interestingly, orlistat in the present study had no effect on the initial GLP-1 response, whereas plasma GLP-1 concentrations were lower between 60 and $120 \mathrm{~min}$. This could be due to the fact that after administration of orlistat the rate of energy delivery was faster than on the control day between 0 and $60 \mathrm{~min}$, i.e. both glucose and fatty acids which escaped lipase inhibition would act as stimuli for GLP-1 release [6] (it can be assumed that the dose of orlistat used would result in $~ 50 \%$ lipase inhibition [21]).

While studies are now indicated to evaluate the chronic effects of lipase inhibition on postprandial glycaemia and incretin responses in type 2 diabetes, it seems clear that orlistat has the potential to exacerbate 
the glycaemic responses to meals containing both fat and carbohydrate in this group. It should be recognised that the test meal used in this study had a high fat content, and that many people would at least occasionally consume meals with comparable amounts of fat. The effects of orlistat on the glycaemic response to meals of lower fat and carbohydrate content could well be less marked and now warrant evaluation. However, it is now recognised that, in healthy subjects and type 2 diabetic patients, even minor variations in gastric emptying of carbohydrate may have a major effect on postprandial glycaemia and incretin responses $[4,5,22,23,24,25,26]$.

Postprandial hypotension is now recognised as a major cause of morbidity in patients with type 1 and type 2 diabetes [13, 27]. In older subjects even relatively minor falls in postprandial blood pressure may lead to clinical events [14]. Treatment options have hitherto been primarily based on anecdotal observations, with a focus on the use of dietary manipulation [27]. Despite its prevalence, the pathophysiology of postprandial hypotension remains poorly defined [13, 27]. While insulin has some vasodilatory properties [28], the observation that postprandial hypotension occurs in patients with type 1 diabetes [13], who are by definition insulin-deficient, suggests that plasma or portal insulin concentrations do not contribute significantly to the pathogenesis of postprandial hypotension.

The effects of lipase inhibition on the cardiovascular response to a meal have, to our knowledge, not been evaluated before. Although none of our subjects had autonomic neuropathy, the postprandial fall in systolic blood pressure and rise in heart rate were greater after orlistat. We have established that there is a relationship between the magnitude of the postprandial fall in systolic blood pressure and rise in heart rate with the rate of gastric emptying [16, 29]. In patients with type 2 diabetes [29] and healthy older subjects [16] slowing of gastric emptying and glucose absorption by the addition of guar gum to a glucose drink is associated with an attenuation of the fall in blood pressure. More recently, using direct intraduodenal glucose infusions, we established that the magnitude of the postprandial fall in blood pressure is dependent on the rate of nutrient entry into the small intestine [30]. The fall in systolic blood pressure and the rise in heart rate were substantially greater in response to a $3 \mathrm{kcal} / \mathrm{min}(12.5 \mathrm{~kJ} / \mathrm{min})$ when compared to a $1 \mathrm{kcal} / \mathrm{min}(4.2 \mathrm{~kJ} / \mathrm{min})$ intraduodenal glucose infusion. Interestingly, the latter differences were evident within a few minutes [30], as in the current study, indicating that the presence of only a small amount of glucose can trigger the heart rate response. Given the known effects of lipase inhibition on gastric emptying [6], it is not surprising that the addition of orlistat to a mixed carbohydrate/fat meal resulted in a greater fall in systolic blood pressure and increase in heart rate.
The magnitude of the observed maximum fall in systolic blood pressure after orlistat (mean: $18.3 \pm 4.5 \mathrm{~mm}$ $\mathrm{Hg}$ ) suggests that this effect could be clinically significant. In view of our observations, the effects of acute and chronic lipase inhibition on the cardiovascular response to meals containing fat and carbohydrate in patients with postprandial hypotension, with and without diabetes, warrant evaluation.

In summary, this study established that in type 2 diabetic patients acute administration of the lipase inhibitor, orlistat, had adverse effects on the glycaemic and blood pressure responses to a meal containing both fat and carbohydrate. These observations highlight the importance of fat content in determining the glycaemic response to a meal in patients with type 2 diabetes; they also raise questions about the potential glycaemic and cardiovascular risks associated with the ingestion of high-fat/carbohydrate meals by patients chronically using lipase inhibitors.

Acknowledgements. This study was supported by project grants from the Royal Adelaide Hospital and the National Health and Medical Research Council (NH\&MRC) of Australia. Dr Jones' salary is derived from a Fellowship jointly awarded by the NH\&MRC and Diabetes Australia. Dr FeinleBisset's salary is provided by an NH\&MRC Career Development Award.

\section{References}

1. Bastyr EJ 3rd, Stuart CA, Brodows RG et al. (2000) Therapy focused on lowering postprandial glucose, not fasting glucose, may be superior for lowering HbA1c. IOEZ Study Group. Diabetes Care 23:1236-1241

2. Saydah SH, Miret M, Sung J, Varas C, Gause D, Brancati FL (2001) Postchallenge hyperglycemia and mortality in a national sample of U.S. adults. Diabetes Care 24:1397-1402

3. Del Prato S (2002) In search of normoglycaemia in diabetes: controlling postprandial glucose. Int $\mathrm{J}$ Obes Relat Metab Disord 26 [Suppl 3]:S9-S17

4. Horowitz M, Edelbroek MA, Wishart JM, Straathof JW (1993) Relationship between oral glucose tolerance and gastric emptying in normal healthy subjects. Diabetologia 36:857-862

5. Jones KL, Horowitz M, Carney BI, Wishart JM, Guha S, Green L (1996) Gastric emptying in early noninsulin-dependent diabetes mellitus. J Nucl Med 37:1643-1648

6. Pilichiewicz A, O’Donovan D, Feinle C et al. (2003) Effect of lipase inhibition on gastric emptying of, and the glycemic and incretin responses to, an oil/aqueous drink in type 2 diabetes mellitus. J Clin Endocrinol Metab 88:3829-3834

7. Meyer JH, Elashoff JD, Domeck M (1994) Control of canine gastric emptying of fat by lipolytic products. Am J Physiol 266:G1017-G1035

8. Schwizer W, Asal K, Kreiss C et al. (1997) Role of lipase in the regulation of upper gastrointestinal function in humans. Am J Physiol 273:G612-G620

9. Hollander PA, Elbein SC, Hirsch IB et al. (1998) Role of orlistat in the treatment of obese patients with type 2 diabetes. A 1-year randomized double-blind study. Diabetes Care 21:1288-1294 
10. Miles JM, Leiter L, Hollander P et al. (2002) Effect of orlistat in overweight and obese patients with type 2 diabetes treated with metformin. Diabetes Care 25:1123-1128

11. Hanefeld M, Sachse G (2002) The effects of orlistat on body weight and glycaemic control in overweight patients with type 2 diabetes: a randomized, placebo-controlled trial. Diabetes Obes Metab 4:415-423

12. Jansen RW, Hoefnagels WH (1991) Hormonal mechanisms of postprandial hypotension. J Am Geriatr Soc 39:1201-1207

13. Mathias CJ (1991) Postprandial hypotension. Pathophysiological mechanisms and clinical implications in different disorders. Hypertension 18:694-704

14. Jansen RW, Connelly CM, Kelley-Gagnon MM, Parker JA, Lipsitz LA (1995) Postprandial hypotension in elderly patients with unexplained syncope. Arch Intern Med 155:945-952

15. Potter JF, Heseltine D, Hartley G, Matthews J, MacDonald IA, James OF (1989) Effects of meal composition on the postprandial blood pressure, catecholamine and insulin changes in elderly subjects. Clin Sci (Lond) 77:265-272

16. Jones KL, MacIntosh C, Su YC et al. (2001) Guar gum reduces postprandial hypotension in older people. J Am Geriatr Soc 49:162-167

17. Jones KL, Tonkin A, Horowitz M et al. (1998) Rate of gastric emptying is a determinant of postprandial hypotension in noninsulin-dependent diabetes mellitus. Clin Sci (Lond) 94:65-70

18. Feinle C, O'Donovan DG, Doran S et al. (2003) Effects of fat digestion on appetite, APD motility, and gut hormones in response to duodenal fat infusion in humans. Am J Physiol 284:G798-G807

19. Feinle C, Chapman IM, Wishart J, Horowitz M (2002) Plasma glucagon-like peptide-1 (GLP-1) responses to duodenal fat and glucose infusions in healthy and obese men. Peptides 23:1491-1495

20. Beysen C, Karpe F, Fielding BA, Clark A, Levy JC, Frayn KN (2002) Interaction between specific fatty acids, GLP-1 and insulin secretion in humans. Diabetologia 45:1533-1541

21. Kelley DE, Bray GA, Pi-Sunyer FX et al. (2002) Clinical efficacy of orlistat therapy in overweight and obese pa- tients with insulin-treated type 2 diabetes: a 1-year randomized controlled trial. Diabetes Care 25:1033-1041

22. Phillips WT, Schwartz JG, McMahan CA (1993) Reduced postprandial blood glucose levels in recently diagnosed non-insulin-dependent diabetics secondary to pharmacologically induced delayed gastric emptying. Dig Dis Sci 38:51-58

23. Rayner CK, Samsom M, Jones KL, Horowitz M (2001) Relationships of upper gastrointestinal motor and sensory function with glycemic control. Diabetes Care 24:371-381

24. Wishart JM, Horowitz M, Morris HA, Jones KL, Nauck MA (1998) Relation between gastric emptying of glucose and plasma concentrations of glucagon-like peptide-1. Peptides 19:1049-1053

25. Horowitz M, Cunningham KM, Wishart JM, Jones KL, Read NW (1996) The effect of short-term dietary supplementation with glucose on gastric emptying of glucose and fructose and oral glucose tolerance in normal subjects. Diabetologia 39:481-486

26. Berry MK, Russo A, Wishart JM, Tonkin A, Horowitz M, Jones KL (2003) Effect of solid meal on gastric emptying of, and glycemic and cardiovascular responses to, liquid glucose in older subjects. Am J Physiol 284:G655-G662

27. Jansen RW, Lipsitz LA (1995) Postprandial hypotension: epidemiology, pathophysiology, and clinical management. Ann Intern Med 122:286-295

28. Scherrer U, Sartori C (1997) Insulin as a vascular and sympathoexcitatory hormone: implications for blood pressure regulation, insulin sensitivity, and cardiovascular morbidity. Circulation 96:4104-4113

29. Russo A, Stevens JE, Wilson T et al. (2003) Guar attenuates fall in postprandial blood pressure and slows gastric emptying of oral glucose in type 2 diabetes. Dig Dis Sci 48:1221-1229

30. O’Donovan D, Feinle C, Tonkin A, Horowitz M, Jones KL (2002) Postprandial hypotension in response to duodenal glucose delivery in healthy older subjects. J Physiol 540:673-679 